\title{
Is the Wistar Rat a more Suitable Normotensive Control for SHR to Test Blood Pressure and Cardiac Structure and Function?
}

Leonardo MateusTeixeira de Rezende, ${ }^{\circledR}$ Leôncio Lopes Soares, ${ }^{1 \oplus}$ Filipe Rios Drummond, ${ }^{1}{ }^{\oplus}$ Pedro Zavagli Suarez, ${ }^{\circledR}$ Luciano Leite, ${ }^{\circledR}$ Joel Alves Rodrigues, ${ }^{1}{ }^{\circledR}$ Tiago Leal, $^{1}{ }^{\circledR}$ Lukiya Favarato, $^{1}{ }^{\circledR}$ Emily Correna Carlo Reis, ${ }^{\circledR}$ Evandro Favarato, ${ }^{1 \oplus}$ Miguel Carneiro-Júnior, ${ }^{1}$ Antônio José Natali, ${ }^{\circledR}$ Cândido Coimbra, ${ }^{\circledR}{ }^{\circledR}$ Thales Prímola-Gomes $^{1}{ }^{\circledR}$

Universidade Federal de Viçosa, ${ }^{1}$ Viçosa, MG - Brazil

Universidade Federal de Minas Gerais, ${ }^{2}$ Belo Horizonte, MG - Brazil

\section{Abstract}

Background: There are divergences in the literature regarding the experimental model (Wistar-WIS or Wistar Kyoto-WKY) to be used as a Spontaneously Hypertensive Rat (SHR) control. The characterization of these models in terms of cardiovascular parameters provides researchers with important tools at the time of selection and application in scientific research.

Objective: The aim of this study was to evaluate the use of WIS and WKY as a Spontaneously Hypertensive Rat (SHR) control by assessing the long-term behavior of blood pressure and cardiac structure and function in these strains.

Methods: To this end, WIS, WKY, and SHR underwent longitudinal experiments. Blood pressure and body mass were measured every two weeks from the 8 th to the 72 nd. Echocardiographic analysis was performed in all groups with 16, 48, and 72 weeks of life. After having applied the normality test, the Two-Way ANOVA of repeated measures followed by the Tukey post hoc test was used. A significance level of $5 \%$ was established .

Results: The WIS group showed higher body mass ( $<<0.05)$, while the WKY and SHR presented higher body mass variation over time $(\mathrm{p}<0.05)$. SHR exhibited increased values of systolic, diastolic, and mean blood pressure when compared to WKY and WIS, whereas the WKY generally showed higher values than WIS $(p<0.05)$. Regarding the cardiac function, SHR showed reduced values, while the WKY presented an early decrease when compared to WIS with aging $(\mathrm{p}<0.05)$.

Conclusion: WIS is a more suitable normotensive control for SHR than WKY in experiments to test blood pressure and cardiac structure and function.

Keywords: Hypertension; Laboratory animals; Blood pressure; Heart.

\section{Introduction}

Experimental animals are usually applied in the study of human health and disease, including the use of rodents as experimental models for the investigation of biological phenomenon similar to those observed in humans. ${ }^{1-3}$ Among them, the SHR is widely used as a model for the investigation of essential hypertension. ${ }^{3-5}$ For those working with these experimental animals, it is obvious and mandatory to adopt a control group in their experiments.

In this way, two experimental strains are nowadays used as SHR's controls, namely Wistar rats (WIS) ${ }^{6-8}$ or Wistar Kyoto rats (WKY). ${ }^{4,5,9}$ It is a well-known fact that WKY was the SHR background and most used strain as SHR control in scientific research. ${ }^{8,10,11}$ However, the WIS strain has also been used. ${ }^{4,5,9,12}$ Moreover, some previous studies have pointed out limitations in the use of both strains. ${ }^{13-18}$ 
Regarding these limitations, Kurtz \& Morris (1987) studied the biological variability of WKY and SHR in two laboratories in the USA over a 20 -week period. Differences in growth rate and mean arterial pressure (MAP), i.e., in biological variability in the WKY, were found. ${ }^{17}$ In a second study, the same group tested the genetic variability of these strains through genomic analysis and found differences between the WKY of different laboratories and even among animals from the same laboratory. ${ }^{16}$ Evidence also points to the presence of increased sympathetic activity in WKY, as shown by baseline resting catecholamine concentrations similar to the levels found in SHR. ${ }^{14,19}$ In another study, Aiello et al. performed a series of experiments in the myocardium of WIS, WKY, and SHR, and found higher left ventricle mass: body mass ratio in WKY when compared to WIS, indicating a hypertrophic process. ${ }^{13}$ The study also found an increase in diastolic papillary muscle stiffness and fibrosis in the left ventricle in the WKY, which was similar to SHR but higher than WIS. ${ }^{13}$

By contrast, limitations have also been highlighted against the use of WIS. First, it is a fact that WIS is not the SHR background. ${ }^{10}$ Furthermore, WIS have higher body mass values compared to WKY and SHR. ${ }^{20}$ This difference brings to light an experimental paradigm when selecting the control group, since when choosing WIS as a control, the researcher will assume that there are two groups with different body weights. ${ }^{21}$.To understand the growth behavior between WIS, WKY, and SHR, a previous study analyzed their physical development immediately after birth, during suckling and weanling. ${ }^{22}$ It was found that WIS showed a higher body mass than WKY and SHR. Additionally, WKY presented a body mass similar to SHR at birth and a higher body mass between the $1^{\text {st }}$ and the $6^{\text {th }}$ weeks of life. ${ }^{22}$ Searching the literature, there is a lack of data that characterizes the two strains to help scientists to select the appropriate control for their experiments. For example, to the best of our knowledge, no study has been conducted to specifically evaluate the use of WIS as an alternative control for WKY.

Therefore, the present study aimed to evaluate the use of WIS and WKY as an SHR control by assessing the long-term behavior of blood pressure, cardiac structure, and function in these strains. We hypothesized that WIS is a more suitable normotensive control for SHR than WKY in experiments to test blood pressure and cardiac structure and function.

\section{Methods}

\section{Animals}

Male WIS, WKY, and SHR rats, in their $8^{\text {th }}$ to $72^{\text {nd }}$ week of life, were used for all experiments. Each experimental group was composed of eight animals $(\mathrm{n}=8)$, and this number was defined using the sample calculation proposed by Armitage and Berry..$^{23}$ The animals were housed in collective cages and allocated in a controlled environment with a light/dark cycle (12/12h), temperature at $22 \pm 2^{\circ} \mathrm{C}$, and had free access to food and water (ad libitum). The animals were obtained from the central biotery of the Federal University of Viçosa (UFV).

\section{Ethical approval}

The experiments were conducted in accordance with the Guide for the Care and Use of in Laboratory Animal principles and approved by the UFV Ethics Committee on the Use of Animals (logged under protocol number 09/2018). All procedures were conducted by a veterinarian.

\section{Body mass}

Body mass (g) was obtained every two weeks, from the 8 th to the 72nd week of life, on an electronic scale (Rochelle, model 3252). To monitor the animals' weight gain behavior, body mass variation $(\Delta)$ was calculated.

\section{Blood pressure}

Systolic Blood Pressure (SBP in $\mathrm{mmHg}$ ) and Diastolic Blood Pressure (DBP in $\mathrm{mmHg}$ ) were measured using the noninvasive method of tail plethysmography (LE5001; Panlab, Barcelona- Spain), as previously described. ${ }^{24}$ Briefly, animals were adapted to a tail cuff and a heating apparatus during five consecutive days. After, animals underwent blood pressure measurements each two weeks. Each measurement was performed three times and the median value was used. All measurements were performed by the same researcher in a quiet environment. ${ }^{25}$ Mean Arterial Pressure (MAP in $\mathrm{mmHg}$ ) was calculated by the following equation: DBP $+1 / 3$ (SBP-DBP).

\section{Echocardiogram}

An echocardiographic analysis was performed in all groups with 16, 48, and 72 weeks of life. The animals underwent an anesthesia inhalation (Isoflurane 1.5\% 
and $100 \% \mathrm{O}_{2}$ at constant flow rate of $1 \mathrm{~L} / \mathrm{min}$ controlled by calibrated vaporizer; Isoflurane, BioChimio, RJBrazil) and placed in a lateral decubitus position. Twodimensional tests were performed with rapid sampling rate (frame rate) of $120 \mathrm{fps}$ and $\mathrm{M}$-mode, using the ultrasound system (MyLabTM30 - Esaote, Genoa- Italy) and $11.0 \mathrm{MHz}$ nominal frequency transducers (phased array). Two-dimensional transthoracic echocardiography and M-mode were obtained at a scanning speed of $200 \mathrm{~mm}$, adjusted according to heart rate. The images were collected according to the recommendations of the American Society of Echocardiography and stored for further analysis. ${ }^{26}$ The left ventricle diameter in diastole (LVDd in $\mathrm{mm}$ ), left ventricle diameter in systole (LVDs in $\mathrm{mm}$ ), interventricular septum in diastole (IVSd in $\mathrm{mm}$ ), interventricular septum in systole (IVSs in $\mathrm{mm}$ ), posterior wall thickness in diastole (PWd in $\mathrm{mm})$, posterior wall thickness in systole (PWs in $\mathrm{mm}$ ), heart rate (HR in bpm), ejection fraction (EF in \%), and shortening fraction (FS in \%) were measured using a modified method recommended by the American Society of Echocardiography for three consecutive cardiac cycles. The examinations were performed by a trained researcher through a single-blinded method. Left ventricle mass (LVM in g) was calculated as follows: ${ }^{27} \mathrm{LVM}=0.8$ (1.04 $\left.(\text { IVSd }+ \text { LVDd }+ \text { PWd })^{3}-(\text { LVDd })^{3}\right) 0.14$. The ratio of LVM to body mass (LVM:BM in mg:g) was calculated as an index of ventricular hypertrophy.

\section{Statistical analysis}

The Shapiro-Wilk test was applied to analyze data normality. Two-Way ANOVA of repeated measures, followed by Tukey post hoc tests, was used to analyze body mass, $\Delta$ body mass, blood pressure, and echocardiographic results. A significance level of 5\% was established. Data are presented as mean \pm standard deviation (SD). Statistical procedures were performed using the SAEG (System for Statistical Analysis) software, version 9.1, from UFV.

\section{Results}

Body mass and body mass variation. Figure $1 \mathrm{~A}$ shows the results for body mass. A strain effect for all groups was found. WIS presented a higher body mass than WKY and SHR during the entire period. Moreover, between the $8^{\text {th }}$ and the $20^{\text {th }}$ weeks, WKY presented a higher body mass when compared to SHR. Figure 1B shows the results for body mass variation. A strain effect for all groups was found. SHR showed higher variation than WIS from the $22^{\text {nd }}$ to the $72^{\text {nd }}$ week and higher variation than WKY at $32^{\text {th }}-50^{\text {th }}$ and $54^{\text {th }}-58^{\text {th }}$ weeks. It was also observed that WKY presented higher variation than WIS at $12^{\text {th }}-16^{\text {th }}$, $24^{\text {th }}-30^{\text {th }}, 34^{\text {th }}-44^{\text {th }}$, and $60^{\text {th }}-64^{\text {th }}$ weeks.

Blood pressure. There was a strain effect for all groups. Figure 2A exhibits the results of SBP. SHR presented higher SBP than WIS and WKY during the entire experimental period. WKY also presented a higher SBP between the $10^{\text {th }}$ and $16^{\text {th }}$ weeks and in the $20^{\text {th }}, 26^{\text {th }}$ and $30^{\text {th }}$ weeks, as well as between the $34^{\text {th }}$ and $72^{\text {nd }}$ weeks. Figure 2B shows the results for DBP. SHR presented a higher DBP than did WIS and WKY in the $8^{\text {th }}$ week. From the $16^{\text {th }}$ week, SHR showed a higher DBP than WIS. In the $18^{\text {th }}$ week, and in-between the $22^{\text {nd }}$ and $72^{\text {nd }}$ weeks, SHR showed a higher DBP than did WKY. WKY presented a higher DBP than did WIS from the week 40 on, specifically in the $40^{\text {th }}, 42^{\text {nd }}, 46^{\text {th }}-50^{\text {th }}, 56^{\text {th }}-62^{\text {nd }}$, and $70^{\text {th }}$ and $72^{\text {nd }}$ weeks. Figure $2 \mathrm{C}$ shows the MAP results. SHR presented a higher MAP value than did WIS during the entire experimental period. Compared to WKY, and in the $8^{\text {th }}, 14^{\text {th }}, 18^{\text {th }}, 22^{\text {nd }}, 24^{\text {th }}$, and $30^{\text {th }}-72^{\text {nd }}$ weeks, SHR presented an increased MAP. WKY presented a higher MAP than did WIS in the $20^{\text {th }}, 26^{\text {th }}, 28^{\text {th }}, 32^{\text {nd }}, 40^{\text {th }}-48^{\text {th }}$, $54^{\text {th }}-58^{\text {th }}, 70^{\text {th }}$, and $72^{\text {nd }}$ weeks. Finally, in the SHR group, a time-dependent increase was observed in SBP, DBP, and MAP from the $28^{\text {th }}$ week on.

Echocardiographic parameters. Figure 3 displays the representative echocardiographic images of animals with 16, 48 , and 72 weeks of life. Tab. 1 shows structural and functional echocardiographic results. Concerning cardiac structure, there was a strain effect for all groups for LVDd. WKY presented a lower LVDd than did WIS and SHR in the $16^{\text {th }}$ week. In the $48^{\text {th }}$ and $72^{\text {nd }}$ weeks, WIS presented a higher LVDd than WKY. An aging effect was also observed. WIS and WKY showed an increase in LVDd in the $48^{\text {th }}$ and $72^{\text {nd }}$ weeks when compared to the $16^{\text {th }}$ week. For LVDs, both strain and aging effects were observed. SHR showed higher LVDs than WIS and WKY. WKY presented lower LVDs when compared to WIS in the $16^{\text {th }}$ week. WIS and WKY presented increased LVDs in the $48^{\text {th }}$ and $72^{\text {nd }}$ weeks as compared to the $16^{\text {th }}$ week. A strain effect was observed for PWd. WKY and SHR presented a higher PWd when compared to WIS in the $48^{\text {th }}$ and $72^{\text {nd }}$ weeks. No differences were observed for PWs. When analyzing the thickness of the interventricular septum, no differences were found. For LVM, both strain and aging effects were found. SHR presented higher LVM when compared to WIS and WKY in the $16^{\text {th }}, 48^{\text {th }}$, and 


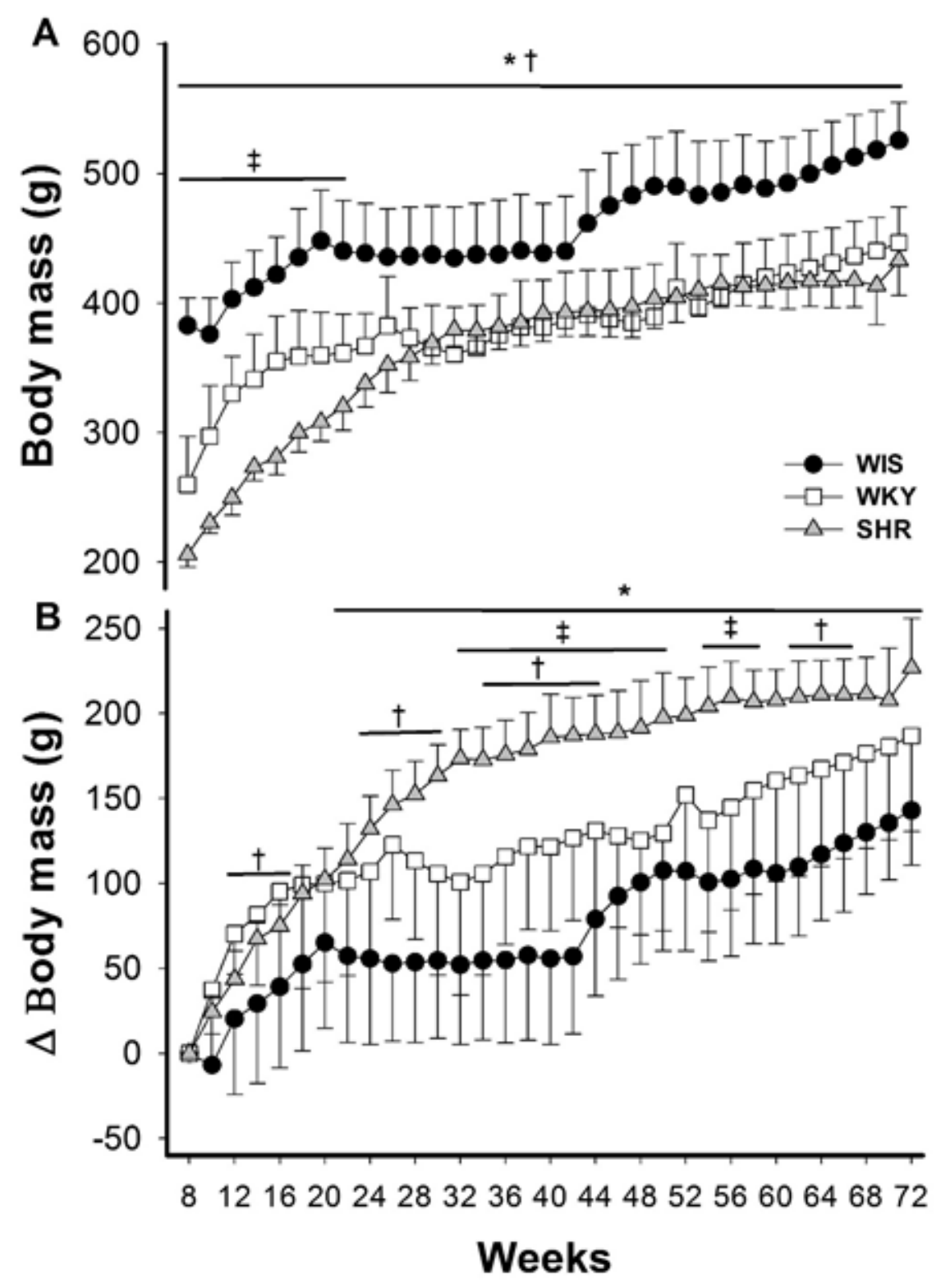

Figure 1 - Long-term behavior of ejection fraction (A) and shortening fraction (B) of WIS ( $n=8)$, WKY (n=8), and SHR ( $=8)$ at 16,48 , and 72 weeks. Data are presented as mean \pm SD. Statistical significance $(p<0.05)$ is shown as follows: $\ddagger=S H R$ vs. WKY; ${ }^{*}=$ SHR vs. WIS; $\S=48$ vs. $16 ; \#=72$ vs. 16 ; $\mathbb{I I}=72$ vs. 48 .

$72^{\text {nd }}$ weeks. WKY and SHR showed increased LVM in the $48^{\text {th }}$ and $72^{\text {nd }}$ weeks when compared to the $16^{\text {th }}$ week. A strain effect was found for LVM:BM. SHR presented higher LVM:BM when compared to WIS and WKY in the $16^{\text {th }}, 48^{\text {th }}$, and $72^{\text {nd }}$ weeks. Related to HR, no differences were observed.

Figure 4 presents the cardiac function. Both strain and aging effects were found for EF (Figure 4A). SHR displayed a lower EF when compared to WIS and WKY at the $16^{\text {th }}$ week. WIS showed a decreased EF in the $72^{\text {nd }}$ week when compared to the $16^{\text {th }}$ week, while WKY had a lower EF in the $48^{\text {th }}$ and $72^{\text {nd }}$ weeks when compared to the $16^{\text {th }}$ week. Regarding SF (Figure 4B), both strain and aging effects were observed. SHR presented a lower SF when compared to WIS and WKY in the $16^{\text {th }}$ week. WKY exhibited a decreased SF in the $48^{\text {th }}$ and $72^{\text {nd }}$ weeks when compared to the $16^{\text {th }}$ week, while WIS presented a decrease in SF only in the $72^{\text {nd }}$ week as compared to the $16^{\text {th }}$ and $48^{\text {th }}$ weeks. 

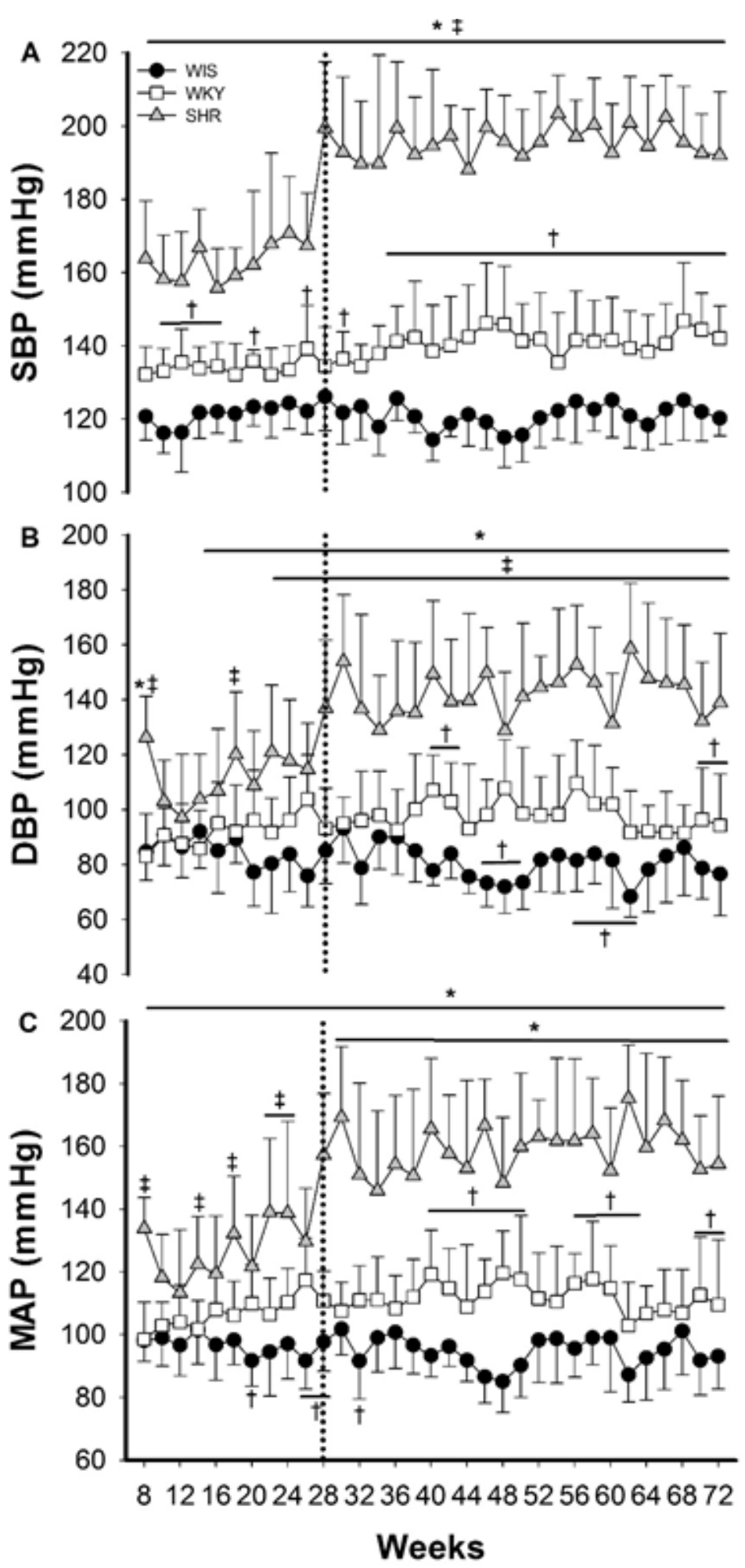

Figure 2 - Long-term behavior of SBP (A), DBP (B) and MAP (C) of WIS ( $n=8)$, WKY $(n=8)$, and SHR ( $n=8)$. The dotted line indicates the moment of significant increase in SHR. Data are presented as mean \pm SD. Statistical significance $(p<0.05)$ are showed as follows: $t=$ WIS vs. WKY; $\ddagger=$ WKY vs. SHR; * = WIS vs. SHR. 


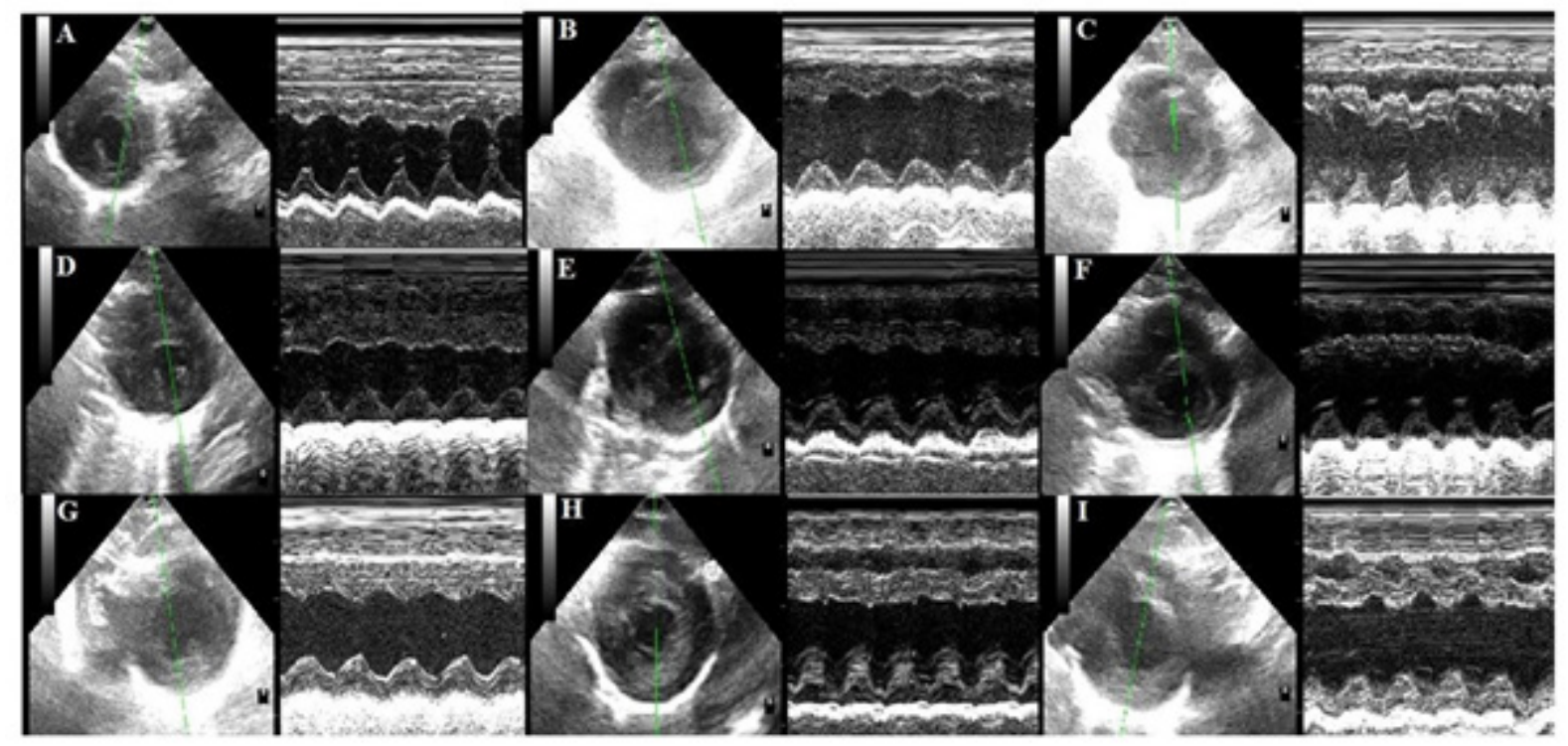

Figure 3 - Representative echocardiographic images of animals at 16, 48, and 72 weeks of life. A= WIS16; B= WIS48; C= WIS72; D= WKY16; E= WKY48; F= WKY72; G= SHR16; H= SHR48; I= SHR72.

\section{Discussion}

The present study assessed the long-term behavior of blood pressure and cardiac structure and function in SHR and both WIS and WKY as controls. For this purpose, the present study assessed blood pressure, cardiac structure, and function over a 72-week period. The results confirmed our hypothesis that, regardless of body weight variations, when the cardiovascular issue is considered to select the control group, WIS is a more suitable normotensive control for SHR than WKY.

Our main findings were: 1 ) The blood pressure values in WKY were intermediate between SHR and WIS and close to hypertension borderline. WIS showed pressure values that were more consistent with those expected for normotensive rats; and 2) WKY presented earlier reductions in cardiac function when compared to WIS.

The correct choice of the control group is essential and has great importance, as it allows one to analyze one variable at a time, making it possible to isolate the variable of interest. ${ }^{28,29}$ For to achieve such purpose, the scientific research must be systematically planned and executed, using appropriate methods and tools..$^{30}$ Usually, the use of SHR as a model of essential hypertension often requires a normotensive group as a control. ${ }^{4,5,31}$ However, researchers face an experimental paradigm, since they must choose controls that match by body mass or by age. . $^{41,22,32}$

Our study found important differences in the body mass and body mass variation among the tested strains over a 72-week period. During their entire life period, WIS presented a higher body mass than did WKY and SHR. However, body mass variation was higher in WKY and SHR strains, which indicates accentuated growth in these strains. A previous work evaluated the food intake of five experimental strains, including WIS, WKY, and SHR, and found increased food consumption in WKY and SHR, which can explain the higher body mass variation observed here. ${ }^{32}$ However, it is important to highlight that the development of hypertension in SHR is agedependent rather than body mass-dependent. ${ }^{21}$

According to Okamoto and Aoki (1963), the reference value to classify rats as hypertensive is SBP above 150 mmHg. ${ }^{10}$ The experimental animals in the present study were classified as follows: WIS - normotensive (116-126 $\mathrm{mmHg}$ ); WKY - normotensive (132-146 $\mathrm{mmHg}$ ); and SHR - hypertensive (155-203 mmHg). This profile was also reflected in altered MAP results. Despite the fact that WIS and WKY were classified as normotensive, it is important to note that the WKY presented higher 


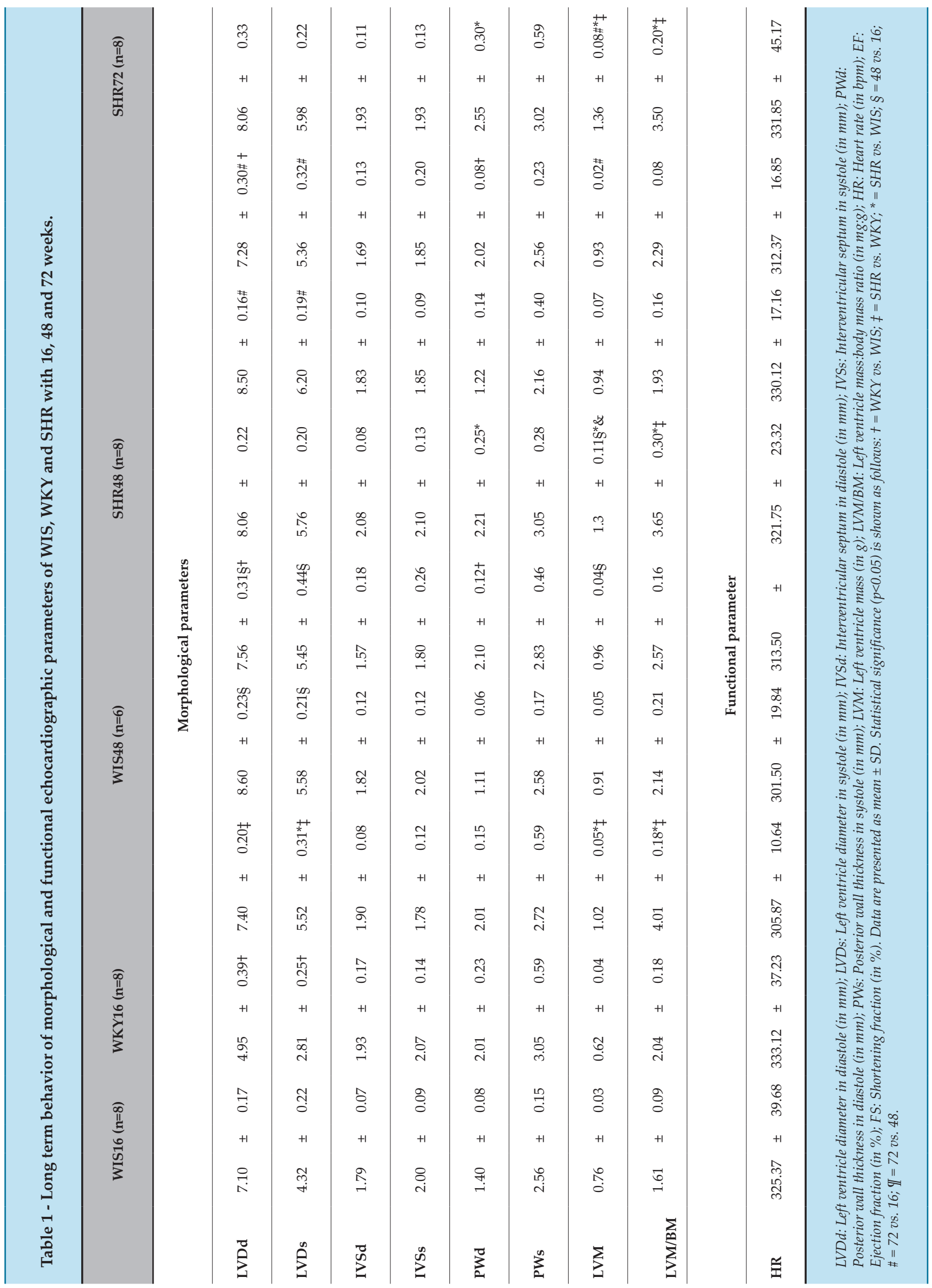



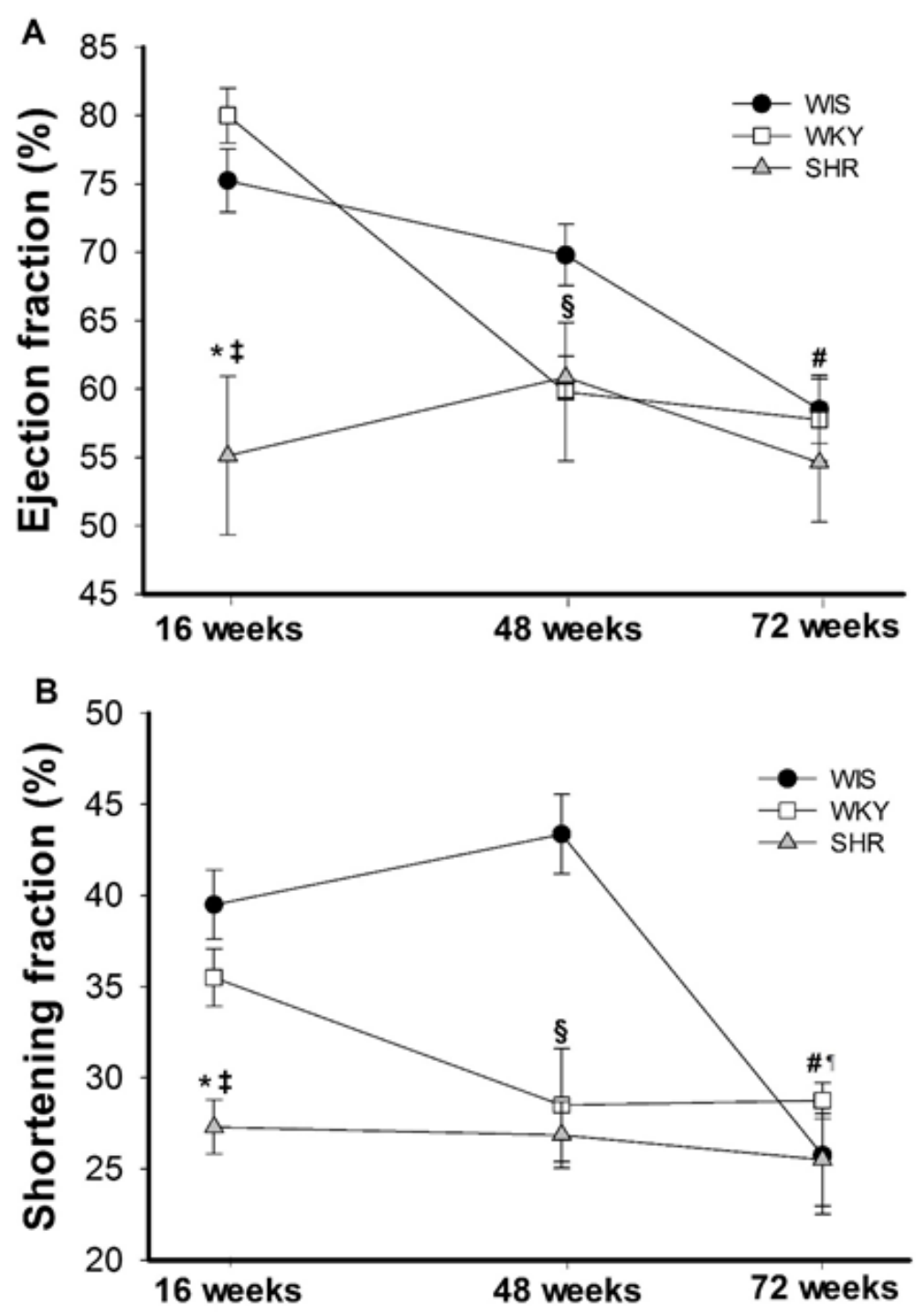

Figure 4 - Long-term behavior of ejection fraction (A) and shortening fraction (B) of WIS ( $n=8)$, WKY (n=8) and SHR ( $=8)$ with 16, 48 and 72 weeks. Data are presented as mean $\pm S D$. Statistical significance $(p<0.05)$ are showed as follows: $\ddagger=$ SHR vs. WKY; ${ }^{*}=S H R$ vs. WIS; $\S=48$ vs. 16 ; $\#=72$ vs. 16 ; $\mathbb{I}=72$ vs. 48 .

SBP values than WIS and, more importantly, close to a hypertension borderline. It is well-known that the chronic increase in blood pressure can lead to such consequences as left ventricular concentric hypertrophy, arterial stiffness, stroke, myocardial infarction, and heart failure. ${ }^{33-36}$ Moreover, previous studies have shown divergent blood pressure variability among the WKY from different laboratories. ${ }^{16,17}$ Such differences have been confirmed by several studies that classified WKY as both normotensive ${ }^{8,13}$ and hypertensive. ${ }^{6,711,20,37}$ It is noteworthy that no previous work was found when assessing the biological variability of WIS. Thus, the long-term behavior of blood pressure observed in the WKY group allows for its use, though it draws attention and requires caution in the use of these animals as an SHR control.

It is also important to mention the abrupt increase in SBP, DBP, and MAP in SHR in the $28^{\text {th }}$ week. Such results may be explained by understanding the disease progression in SHR. ${ }^{3,38}$ Previous results show blood vessel hypertrophy in the $4^{\text {th }}$ week of life as the first event related to the disease, although the SBP values are 
still more normotensive in nature. ${ }^{39}$ Additionally, the prehypertension stage can last up to 4 th months of life. ${ }^{3}$ After, compensated hypertension sets in, in which the SHR reaches the SBP of $150 \mathrm{mmHg}$ with an increase in the thickness of the cardiac walls coupled with the reductions in the left ventricular internal diameter. This structural rearrangement occurs to cope with the stress imposed by pressure overload on the cardiac walls and promote maintenance of systolic function, and may last until the sixth month of life. ${ }^{40,41}$ Our data show that around the $6^{\text {th }}$ to, $7^{\text {th }}$ month established and balanced hypertension is observed, characterizing the stage of decompensated hypertension. ${ }^{38,41}$ With disease progression, between the $18^{\text {th }}$ and $24^{\text {th }}$ months of life, SHR reaches the heart failure stage. ${ }^{41}$ In fact, 20-weekold SHR presents a higher SBP when compared to that of 12-week-old animals, ${ }^{42}$ and equivalent results have already been demonstrated by others. . $^{39,42}$

Regarding the cardiac structure assessed by echocardiography, it was observed that WKY at 16 weeks presented lower LVDd and LVDs when compared to WIS and SHR. Moreover, LVDd was also lower in WKY than in WIS animals at 48 and 72 weeks of life. Both WIS and WKY presented increased LVDd and LVDs with aging. In addition, WKY and SHR showed a higher PWd when compared to the WIS in weeks 48 and 72. Left ventricular remodeling is a process by which the cardiac chamber undergoes changes in its shape, size, and function, and may occur as a result of either physiology (i.e. physical training) or pathophysiology (i.e. hypertension stimuli). ${ }^{43}$ Pathophysiological hypertrophy is normally caused by a high blood pressure overload in the cardiac chambers, leading to reductions in the left ventricular diameter, accompanied by increases in the ventricular walls' width. ${ }^{44}$

Morphological changes directly affect the cardiovascular function. The long-term pathological hypertrophy causes cardiac adverse remodeling of the extracellular matrix, such as increases in collagen content, which promote tissue stiffening, thus affecting the diastolic function and leading to a systolic dysfunction..$^{45}$ The left ventricle is responsible for blood ejection and its morphology is crucial for pump appropriated functioning. ${ }^{40,46}$ We demonstrated that the SHR group presented higher values for LVM than did WIS and WKY. With aging, both WKY and SHR exhibited significant increases in LVM when compared to the $16^{\text {th }}$ week. To confirm the pathological hypertrophic process, the LVM/ $\mathrm{BM}$ ratio was calculated, ${ }^{45}$ and hypertrophy was not found in the WKY strain. Thus, probably the overload imposed by the increased SBP was not enough to promote pathological hypertrophy in WKY. However, a previous work found that the hemodynamic cardiac load is more evident in isolated cardiomyocytes than in an entire ventricle. ${ }^{7}$ In addition to left ventricle analysis, the PWd of the WKY and SHR was larger when compared to the WIS at weeks 48 and 72.

Concerning cardiac function, different from another study that showed late decreases in the cardiac function of SHR over lifetime, ${ }^{31}$ in the present study, we found decreases in both EF and FS in SHR from the $16^{\text {th }}$ week on. The WKY, however, presented normal values for EF and FS in the $16^{\text {th }}$ week, followed by reductions in the $48^{\text {th }}$ and $72^{\text {nd }}$ weeks. This finding is in agreement with previous studies, showing that WKY had diastolic dysfunction as a consequence of increased pressure overload..$^{13}$ Finally, cardiac dysfunction was observed in WIS only in the $72^{\text {nd }}$ week.

This work has some limitations. Since our proposal was to verify the animals' echocardiographic parameters in the $16^{\text {th }}$ week of life, we did not perform an echocardiographic examination in the $8^{\text {th }}$ week, the pre-hypertensive stage. Unfortunately, the lack of this information did not allow the discussion of our results to expand into a broader age range. Furthermore, the animals' food intake was not monitored, and this factor may have affected the weight gain of the animals. It is possible that differences observed in the body mass may well be related to different values of food intake. However, to confirm such a possibility, future experiments of this nature are warranted.

\section{Conclusions}

In conclusion, Wistar rats are a more suitable normotensive control for SHR than Wistar Kyoto rats in experiments to test issues related to blood pressure, cardiac structure, and function in different ages inasmuch as Wistar Kyoto rats exhibit early reductions in cardiac function and blood pressure values in the upper limit of normal blood pressure.

\section{Author contributions}

Conception and design of the research: Rezende LMT, Reis ECC, Favarato LSC, Carneiro-Júnior MA, Natali AJ, Coimbra CC, Prímola-Gomes TN. Acquisition of data: Rezende LMT, Reis ECC, Favarato LSC, Soares LL, Drummond FR, Suarez PZ, Leite LB, Rodrigues JA, Leal, TF, Favarato ES. Analysis and interpretation of the data: Rezende 
LMT, Reis ECC, Favarato LSC, Soares LL, Drummond FR, Suarez PZ, Leite LB, Rodrigues JA, Leal, TF, Favarato ES, Natali AJ, Coimbra, CC. Statistical analysis: Rezende LMT, Soares LL, Drummond FR, Leal TF, Carneiro-Júnior MA, Prímola-Gomes TN. Obtaining financing: Prímola-Gomes TN. Natali, AJ. Writing of the manuscript: Rezende LMT, Prímola-Gomes TN. Natali, AJ. Critical revision of the manuscript for intellectual content: Rezende LMT, PrímolaGomes TN. Natali AJ, Coimbra CC.

\section{Potential Conflict of Interest}

No potential conflict of interest relevant to this article was reported.

\section{Sources of Funding}

This study was supported in part by CNPq (Conselho Nacional de Desenvolvimento Científico e Tecnológico), CAPES (Coordenação de Aperfeiçoamento de Pessoal de Nível Superior), and FAPEMIG (Fundação de Amparo à Pesquisa do Estado de Minas Gerais). AJ Natali is a CNPq fellow.

\section{Study Association}

This article is part of the thesis of Doctoral submitted by Leonardo Mateus Teixeira de Rezende, from Universidade Federal de Viçosa.

\section{Ethics approval and consent to participate}

This article does not contain any studies with human participants or animals performed by any of the authors.

rats during exercise: effects of physical training. Arq Bras Cardiol. 2019;112(5):534-42. doi: 10.5935/abc.20190050.

13. Aiello EA, Villa-Abrille MC, Escudero EM, Portiansky EL, Pérez NG, de Hurtado MC, et al. Myocardial hypertrophy of normotensive WistarKyoto rats. Am J Physiol Heart Circ Physiol. 2004;286(4):1229-35. doi: 10.1152/ajpheart.00779.2003.

14. Chiueh CC, McCarty R. Sympatho-adrenal hyperreactivity to footshock stress but not to cold exposure in spontaneously hypertensive rats. Physiol Behav. 1981;26(1):85-9. doi: 10.1016/0031-9384(81)90082-2.

15. Collins HL, Loka AM, Dicarlo SE. Daily exercise-induced cardioprotection is associated with changes in calcium regulatory proteins in hypertensive rats. Am J Physiol Heart Circ Physiol. 2005;288(2):532-40. doi: 10.1152/ ajpheart.00873.2004.

16. Kurtz TW, Montano M, Chan L, Kabra P. Molecular evidence of genetic heterogeneity in Wistar-Kyoto rats: implications for research with the spontaneously hypertensive rat. Hypertension. 1989;13(2):188-92. doi: 10.1161/01.hyp.13.2.188.

17. Kurtz TW, Morris RC Jr. Biological variability in Wistar-Kyoto rats. Implications for research with the spontaneously hypertensive rat. Hypertension. 1987;10(1):127-31. doi: 10.1161/01.hyp.10.1.127.

18. Langen B, Dost R. Comparison of SHR, WKY and Wistar rats in different behavioural animal models: effect of dopamine D1 and alpha2 agonists. Atten Defic Hyperact Disord. 2011;3(1):1-12. doi: 10.1007/s12402-0100034-y.

19. Hendley ED, Cierpial MA, McCarty R. Sympathetic-adrenal medullary response to stress in hyperactive and hypertensive rats. Physiol Behav. 1988;44(1):47-51. doi: 10.1016/0031-9384(88)90344-7.

20. Sanada LS, Tavares MR, Neubern MC, Salgado HC, Fazan VP. Can Wistar rats be used as the normotensive controls for nerve morphometry investigations in spontaneously hypertensive rats (SHR)? Acta Cir Bras. 2011;26(6):514-20. doi: 10.1590/s0102-86502011000600018.

21. Hom S, Fleegal MA, Egleton RD, Campos CR, Hawkins BT, Davis TP. Comparative changes in the blood-brain barrier and cerebral infarction of SHR and WKY rats. Am J Physiol Regul Integr Comp Physiol. 2007;292(5):1881-92. doi: 10.1152/ajpregu.00761.2005.

22. Gattone $\mathrm{VH} 2$ nd. Body weight of the spontaneously hypertensive rat during the suckling and weanling periods. Jpn Heart J. 1986;27(6):881-4. doi: $10.1536 /$ ihj.27.881. 
23. Armitage P, Berry G, editors. Statistical methods in medical research. 2nd ed. Oxford: Blackwell; 1987.

24. Byrom FB, Wilson C. A plethysmographic method for measuring systolic blood pressure in the intact rat. J Physiol. 1938;93(3):301-4. doi: 10.1113/ jphysiol.1938.sp003641.

25. Fink GD. Does Tail-Cuff Plethysmography Provide a Reliable Estimate of Central Blood Pressure in Mice? J Am Heart Assoc. 2017;6(6):e006554. doi: 10.1161/JAHA.117.006554.

26. Sahn DJ, DeMaria A, Kisslo J, Weyman A. Recommendations regarding quantitation in M-mode echocardiography: results of a survey of echocardiographic measurements. Circulation. 1978;58(6):1072-83. doi: 10.1161/01.cir.58.6.1072.

27. Brown L, Fenning A, Chan V, Loch D, Wilson K, Anderson B, et al. Echocardiographic assessment of cardiac structure and function in rats. Heart Lung Circ. 2002;11(3):167-73. doi: 10.1046/j.1444-2892.2002.00148.x.

28. Kinser PA, Robins JL. Control group design: enhancing rigor in research of mind-body therapies for depression. Evid Based Complement Alternat Med. 2013;2013:140467. doi: 10.1155/2013/140467.

29. Pithon MM. Importance of the control group in scientific research. Dental Press J Orthod. 2013;18(6):13-4. doi: 10.1590/s2176-94512013000600003.

30. Gu J, Li XB, Tian LH. Scientific research accomplishment of medical staff. Zhonghua Yi Xue Za Zhi. 2013;93(10):735-7.

31. Slama M, Ahn J, Varagic J, Susic D, Frohlich ED. Long-term left ventricular echocardiographic follow-up of SHR and WKY rats: effects of hypertension and age. Am J Physiol Heart Circ Physiol. 2004;286(1):181-5. doi: 10.1152/ajpheart.00642.2003.

32. Gordon CJ, Phillips PM, Johnstone AF. Impact of genetic strain on body fat loss, food consumption, metabolism, ventilation, and motor activity in free running female rats. Physiol Behav. 2016;153:56-63. doi: 10.1016/j. physbeh.2015.10.025.

33. Chae CU, Pfeffer MA, Glynn RJ, Mitchell GF, Taylor JO, Hennekens CH. Increased pulse pressure and risk of heart failure in the elderly. JAMA. 1999;281(7):634-9. doi: 10.1001/jama.281.7.634.

34. Levy D, Larson MG, Vasan RS, Kannel WB, Ho KK. The progression from hypertension to congestive heart failure. JAMA. 1996;275(20):1557-62.

35. McCrossan ZA, Billeter R, White E. Transmural changes in size, contractile and electrical properties of SHR left ventricular myocytes during compensated hypertrophy. Cardiovasc Res. 2004;63(2):283-92. doi: 10.1016/j.cardiores.2004.04.013.
36. Pawlush DG, Moore RL, Musch TI, Davidson WR Jr. Echocardiographic evaluation of size, function, and mass of normal and hypertrophied rat ventricles. J Appl Physiol. 1993;74(5):2598-605. doi: 10.1152/ jappl.1993.74.5.2598.

37. Bomfim GHS, Méndez-López I, Fernández-Morales JC, Padín JF, Jurkiewicz A, Jurkiewicz NH, et al. Electrophysiological properties and augmented catecholamine release from chromaffin cells of WKY and SHR rats contributing to the hypertension development elicited by chronic EtOH consumption. Eur J Pharmacol. 2017;803:65-77. doi: 10.1016/j.ejphar.2017.03.017.

38. Boluyt MO, Bing OH, Lakatta EG. The ageing spontaneously hypertensive rat as a model of the transition from stable compensated hypertrophy to heart failure. Eur Heart J. 1995;16:19-30. doi: 10.1093/ eurheartj/16.suppl_n.19.

39. Adams MA, Bobik A, Korner PI. Differential development of vascular and cardiac hypertrophy in genetic hypertension. Relation to sympathetic function. Hypertension. 1989;14(2):191-202. doi: 10.1161/01.hyp.14.2.191.

40. Grossman W. Cardiac hypertrophy: useful adaptation or pathologic process? Am J Med. 1980;69(4):576-84. doi: 10.1016/0002-9343(80)90471-4.

41. Bing OH, Brooks WW, Robinson KG, Slawsky MT, Hayes JA, Litwin SE, et al. The spontaneously hypertensive rat as a model of the transition from compensated left ventricular hypertrophy to failure. J Mol Cell Cardiol. 1995;27(1):383-96. doi: 10.1016/s0022-2828(08)80035-1.

42. Bacharova L, Kyselovic J, Klimas J. The initial stage of left ventricular hypertrophy in spontaneously hypertensive rats is manifested by a decrease in the QRS amplitude/left ventricular mass ratio. Clin Exp Hypertens. 2004;26(6):557-67. doi: 10.1081/ceh-200031835.

43. Ganau A, Devereux RB, Roman MJ, de Simone G, Pickering TG, Saba PS et al. Patterns of left ventricular hypertrophy and geometric remodeling in essential hypertension. J Am Coll Cardiol. 1992;19(7):1550-8. doi: 10.1016/0735-1097(92)90617-v

44. Grant C, Greene DG, Bunnell IL. Left ventricular enlargement and hypertrophy. A clinical and angiocardiographic study. Am J Med. 1965;39(6):895-904. doi: 10.1016/0002-9343(65)90111-7.

45. Brower GL, Gardner JD, Forman MF, Murray DB, Voloshenyuk T, Levick SP, et al. The relationship between myocardial extracellular matrix remodeling and ventricular function. Eur J Cardiothorac Surg. 2006;30(4):604-10. doi: 10.1016/j.ejcts.2006.07.006.

46. LINZBACH AJ. Heart failure from the point of view of quantitative anatomy. Am J Cardiol. 1960;5:370-82. doi: 10.1016/0002-9149(60)90084-9. 